\title{
Serological evidence of exposure to zoonotic tick-borne bacteria in pheasants (Phasianus colchicus)
}

\author{
Valentina Virginia Ebani', Fabrizio Bertelloni ${ }^{1}$, Paolo Mani ${ }^{1}$ \\ ${ }^{1}$ Department of Veterinary Science, University of Pisa \\ Ebani V V, Bertelloni F, Mani P. Serological evidence of exposure to zoonotic tick-borne bacteria in pheasants (Phasianus colchicus). Ann Agric \\ Environ Med. 2017; 24(1): 82-85. doi: 10.5604/12321966.1234004
}

\section{Abstract}

Introduction and objective. Previous studies on tick-borne pathogens in the avian population have focused mainly on the detection of the agents in ticks collected from birds, but data about the presence of tick-borne bacteria in these animals are scant. The aim of the presented study was to verify the exposure to some zoonotic tick-borne bacteria, in particular, Anaplasma phagocytophilum, Borrelia burgdorferi sensu lato, Coxiella burnetii, and the Rickettsia species of the Spotted Fever Group (SFG), in pheasants (Phasianus colchicus) living in a central Italy area, characterized by conditions favourable for the diffusion of the ticks.

Materials and method. Blood serum samples from 276 farm-reared pheasants were examined by indirect immunofluorescence antibody test to detect antibodies against the 4 reported pathogens.

Results. A total of 124 (44.92\%) birds resulted as seropositive: in particular $3(1.08 \%)$ to C. burnetii, 31 (11.23\%) to A. phagocytophilum, 46 (16.67\%) to B. burgdorferi s.I., 49 (17.75\%) to SFG Rickettsia spp. antigens. Three pheasants resulted positive both to A. phagocytophilum and B. burgdorferi s.I. antigens, whereas 2 - both to B. burgdorferi s.I. and SFG Rickettsia spp. antigens. The antibody titers varied from 1:40-1:320.

Conclusions. The obtained results show that the pheasants had developed antibodies to the investigated tick-borne agents. For this reason, they seem to be involved in the epidemiology of the studied tick-borne bacteria.

\section{Key words}

pheasant (Phasianus colchicus); Anaplasma phagocytophilum; Borrelia burgdorferi s.l.; Coxiella burnetii; SFG Rickettsia spp.; IFAT

\section{INTRODUCTION}

The common pheasant (Phasianus colchicus) is a bird of the Phasianidae family. It is one of the most hunted birds worldwide; for this purpose, it has been introduced in many regions, and is also common on game farms where it is commercially bred [1]. In central Italy, several pheasants farms are indeed spread throughout the region, located in rural areas, rich in vegetation where wild animals and ticks are often present. Wild mammals are demonstrated to be reservoirs of tick-borne pathogens, and often the cause of disease in domestic animals and humans [2].

Wild birds are often carriers of infected ticks [3], in particular, the most common hard tick species associated with avian hosts in various European Countries is Ixodes ricinus, which is known to be a vector of several important zoonotic bacteria [4].

Previous studies on tick-borne pathogens in the avian population have focused mainly on the detection of the agents in ticks collected from birds. A recent molecular study has been carried out on ticks collected from migratory birds in Italy, which found that they are often carriers of ticks, in particular Hyalomma marginatum, infected by Rickettsia sp, B. burgdorferi s.l., C. burnetii and Babesia microti [5]. However, data about the detection of tick-borne bacteria in birds are scant $[4,6,7,8]$, and in particular, there is no

\footnotetext{
Address for correspondence: Valentina Virginia Ebani, Department of Veterinary Science, University of Pisa

E-mail: valentina.virginia.ebani@unipi.it

Received: 25 November 2015; accepted: 27 September 2016; first published on January 2017
}

data available on the prevalence of these pathogens among birds in Italy.

\section{OBJECTIVE}

The aim of the presented study was to verify the exposure to some zoonotic tick-borne bacteria, in particular, Anaplasma phagocytophilum, Borrelia burgdorferi sensu lato, Coxiella burnetii, and Rickettsia species of the Spotted Fever Group (SFG), in pheasants in an area of central Italy characterized by conditions favourable for the diffusion of ticks, because of the abundant vegetation and presence of wild animals.

\section{MATERIALS AND METHOD}

Study area. The birds lived in an area of Tuscany $\left(43^{\circ} 43^{\prime} \mathrm{N}\right.$, $10^{\circ} 20^{\prime} \mathrm{E}$, at sea level), characterized by a mild climate and abundant vegetation, mainly composed of pines (Pinus pinea and Pinea pinaster), oak (Quercus ilex), ash (Fraxinus sp.), alder (Alnes sp.) and poplar (Populus alba). Ixodes ricinus is the most common hard tick species found in this area, but Dermacentor marginatus, Haemaphysalis punctata, Rhipicephalus sp. and Hyalomma sp. are also present [9]. Several different bird species live usually in this area, as well as various large and small mammals, such as fallow deer (Dama dama), wild boar (Sus scrofa), red fox (Vulpes vulpes), red squirrel (Sciurus vulgaris), common rabbit (Oryctolagus cuniculus), European badger (Meles meles), hedgehog (Erinaceus europaeus), and different small rodent species. 
Farm animals, in particular cattle and horses employed for trekking, are present.

Samples. Blood serum samples from 276 pheasants (Phasianus colchicus), kept at $-20^{\circ} \mathrm{C}$ in the seroteca of the Avian Pathology Section of the Department of Veterinary Science at the University of Pisa, were tested by indirect immunofluorescence antibody test (IFAT) for the presence of antibodies to A. phagocytophilum, B. burgdorferi s.l., C. burnetii, and SFG Rickettsia spp.

During 2007-2008, blood samples from the brachial vein of 151 females and 125 males, all 8-12 weeks old, were collected during periodical health monitoring of the birds. The pheasants lived fenced-in, without direct contact with other birds or mammals. All of them were mainly bred for releasing in restocking areas, and in a few cases, they were sold for personal meat consumption and introduction in hobbyist small farms.

Serological tests. The tests were carried out on 4 types of commercial IFAT slides prepared with A. phagocytophilum, B. burgdorferi s.l., C. burnetii and R. conorii (SFG) antigens (Fuller Laboratories Fullerton, California, USA), respectively. Blood sera were diluted 1:40 in phosphate buffered saline (PBS), and incubated on wells of the slides in a humidified chamber at $37^{\circ} \mathrm{C}$ for $30 \mathrm{~min}$. The slides were rinsed 3 times in PBS containing 0.4\% Tween 80 (Sigma-Aldrich, St. Louis, Missouri, USA), once in distilled water, then air-dried. Each well of the slides was probed with fluorescein isothiocyanateconjugated rabbit anti-Chicken IgG (Sigma-Aldrich) diluted 1:30 in Evans Blue (Sigma-Aldrich) solution and incubated at $37^{\circ} \mathrm{C}$ in a humid chamber for $30 \mathrm{~min}$. The slides were washed and dried as described above and examined with a fluorescence microscope. Negative and positive controls were included in each test: PBS, instead of serum, probed with the anti-chicken IgG conjugate used as negative control; one human serum reactive for each agent (Fuller Laboratories) respectively, probed with anti-human IgG conjugate (Fuller Laboratories), was included as positive control.

Samples scored positive at 1:40 cut-off dilution were 2-fold serially diluted, from 1:80 to 1:320, to determine the endpoint titre. Scores from 1-4 were assigned to the intensity of specific fluorescence, the antibody titre was defined as the major dilution with $a \geq 2$ score.

Positive reactions were observed with the human sera used as positive controls, whereas no fluorescent reactions were observed when PBS was included as the negative control.

Statistical analysis were carried out by $\chi^{2}$ test $(\mathrm{P}<0.05)$ to compare the results in relation to bird gender.

\section{RESULTS}

From the 276 blood serum samples tested, a total of 124 (44.92\%), 56 (56/125, 44.8\%) males and 68 (68/151, 45\%) females, resulted seropositive. In particular, 31 (11.23\%) pheasants showed antibodies to A. phagocytophilum antigen, $46(16.67 \%)$ to $B$. burgdorferi s.l. antigen, 49 (17.75\%) to R. conorii (SFG) antigen, and $3(1.08 \%)$ to C. burnetii antigen. Three samples resulted positive both to A. phagocytophilum and $B$. burgdorferi s.l. antigens and 2 both to $B$. burgdorferi s.l. and SFG Rickettsia spp. antigens. The antibody titers varied from 1:40-1:320 (Tab. 1).
Table 1. Number of pheasants (Phasianus colchicus) resulted seropositive to the different agents according to antibody titer (cut-off 1:40)

\begin{tabular}{|c|c|c|c|c|c|}
\hline \multirow[t]{2}{*}{ Agents } & \multicolumn{4}{|c|}{$\begin{array}{l}\text { No. positive pheasants at the given } \\
\text { antibody titer }\end{array}$} & \multirow[t]{2}{*}{$\begin{array}{l}\text { Total of positive } \\
\text { pheasants }(\% *)\end{array}$} \\
\hline & $1: 40$ & $1: 80$ & $1: 160$ & $1: 320$ & \\
\hline A.phagocytophilum & 14 & 12 & 5 & - & $31(11.23)$ \\
\hline B. burgdorferi s.l. & 15 & 18 & 9 & 4 & $46(16.67)$ \\
\hline SFG Rickettsia spp. & 14 & 18 & 11 & 6 & 49 (17.75) \\
\hline C. burnetii & 3 & - & - & - & $3(1.08)$ \\
\hline
\end{tabular}

* Percentage of positive animals, to each agent, among the 276 tested

No statistical differences were observed when comparing males and females, analyzing the results with $\chi^{2}$ test $(\mathrm{P}<0.05)$.

\section{DISCUSSION}

The test used in the presented study was IFAT which is largely employed for the diagnosis of tick-borne diseases in animals and humans. In particular, IFAT is considered the gold standard serological method for the diagnosis of rickettsioses and anaplasmosis [10], and it is often used for the detection of antibodies against B. burgdorferi s.l. [10] and C. burnetii [11].

A fluorescein isothiocyanate-conjugated rabbit antichicken IgG was used as secondary antibodies, because no commercial conjugate specific to detect pheasant immunoglobulins is available. IgG domains of different bird species are variable and might not present the same homology with chicken antibodies; thus, the secondary antibody used could have negatively influenced the results of IFAT [12]. However, the obtained results revealed the exposure of pheasants to the 4 tick-borne agents studied.

The lowest values of seroprevalence at low antibody titer was observed for C. burnetii, the agent of Q fever, a severe zoonotic disease [13]. Animals and humans usually acquire this bacterium through inhalation of contaminated aerosol and ingestion of milk and dairy products from infected ruminants. Infected animals shed coxiellae mainly in birth products, but also in faeces and urine [14]. More than 40 species of ticks can be naturally infected with $C$. bunetii during a blood meal on infected animals, and transmit the bacterium to other mammals during the next blood meal, or by the aerogenic spread of dried tick faecal excretions, maintaining C. burnetii in wildlife [15].

The low seroprevalence found in the tested pheasants is probably related to the absence of direct or indirect contact with livestock, which usually represent the main source of infection [14], but also to the moderate spreading of the pathogen in the tick population and probably in this geographic area. In fact, previous molecular surveys carried out in mammals and ticks in several areas of Tuscany, including the one under study, have found prevalences for C. burnetii of $5.1 \%$ in hunting dogs [16], 3.75\% in horses [17] and $0 \%$ in ticks [9].

The seroprevalence values against the other agents, which are transmitted only by ticks, in particular ixodid ticks $[18,19,20]$, were higher, about $18 \%$ of pheasants resulted positive to SFG Rickettsia. IFAT, even if considered the gold standard method for the serological diagnosis of rickettsiosis [21], is often not able to differentiate antibodies against the 
species belonging to the Spotted Fever Group [18]. In Italy, several SFG rickettsiae are circulating, as demonstrated by molecular investigations on tick populations. In particular, $R$. conorii, $R$. helvetica, $R$. massiliae, $R$. slovaca, $R$. monacensis, $R$. aeschlimannii, $R$. raoultii, and $R$. africae have been detected $[22,23,24,25,26,27]$. Thus, the observed seroprevalence, in some cases with relevant antibody titers, could be due to the exposure of pheasants to one of the SFG Rickettsia species.

Previous surveys carried out in Europe have found DNA of SFG rickettsiae in ticks collected from birds, underling the role of migratory birds in the dispersal of tick-borne agents. In particular, recent molecular studies have detected Rickettsia spp., mainly R. aeschlimannii and R. africae, in ticks collected from migratory birds in European Mediterranean areas $[5,28]$. However, the competence of birds to function as Rickettsia reservoir capable of transmitting and infecting ticks with rickettsiae is not yet completely understood [29]. A recent study has detected bacteraemia by $R$. helvetica in wild avian hosts in Hungary [4], but further data about Rickettsia spp. infections in birds are not available worldwide.

On the contrary, $B$. burgdorferi s.l., in particular the genospecies B. garinii and B. valaisiana, have long been associated with the avian population [30]. Previous investigations have found that the bird host competency for maintaining and transmitting Borrelia spirochetes varies in different bird species. For example, pheasants in the United Kingdom [31,32] and blackbirds and song thrushes in Central Europe have been shown to be important reservoirs of $B$. garinii and $B$. valaisiana [30, 33, 34, 35]. Moreover, $B$. turdii, a genospecies first reported from Asia, was found in I. ricinus and Ixodes frontalis larvae feeding on blackbirds in Portugal [6].

The presented study detected $16.67 \%$ seroprevalence, with antibody titers ranging from 1:40-1:320, confirming that birds, in particular pheasants, may be infected by B. burgdorferi s.l. The study also detected $11.23 \%$ of A. phagocytophilum seropositive pheasants. Seroprevalence of $13.68 \%$ were previously detected in central Italy during the testing of a total of 2,455 wild and domestic animals: particularly in $46.26 \%$ of fallow deer, $46.15 \%$ of red deer, $16.89 \%$ - horses, $16.78 \%$ - cattle, $12.74 \%$ - sheep, $8.76 \%$ - dogs and $4.16 \%$ of goats resulted positive to A. phagocytophilum [36].

A. phagocytophilum was found by PCR in some avian species (Fringilla coeldos, Passer domesticus, Passer hispaniolensis, Turdus merula, Emberiza cia, Lanius senator, Pica pica, Aegithalos caudatus) [37], but no data are available about $A$. phagocytophilum infection in pheasants. Previous investigations carried out in Europe have focused mainly on the detection of A. phagocytophilum in ticks collected from birds, and have shown that migrating birds may be important in the dispersal of $A$. phagocytophilum infected I. ricinus $[38,39]$.

A. phagocytophilum is currently considered as a single bacterial species. However, a recent study carried out on A. phagocytophilum DNA found in ticks and different vertebrates including birds, identified 4 ecotypes. In particular, ecotypes I, II and III were found in mammals, whereas ecotype IV resulted most likely from association with avian species. These results indicate that the host specialization of $A$. phagocytophilum may occur, and suggests that ecotype IV might be adapted to a life cycle involving exclusively birds and bird-specific vectors [40].

\section{CONCLUSIONS}

To the best of our knowledge, the presented study is the first serological survey that suggests the exposure of pheasants to zoonotic tick-borne pathogens in Italy. The obtained results are not too surprising, considering that the examined birds lived in a geographic area with conditions favouring the diffusion of ticks, and in which arthropod-borne infections have been previously detected in ticks and mammals [9, 26, 41, 42].

The pheasants tested in the current study did not have direct contact with mammals; however, they lived in aviaries enclosed by wire meshes, therefore, they could be reached by ticks disseminated in the environment from other wild animals, including birds.

Farm-reared pheasants are usually released to increase the wild population; however, this common practice may introduce new pathogens into the autochthonous population, as frequently established for parasites [1, 43]. Likewise, the introduction in a new habitat of pheasants infested by infected ticks and/or with active infection by arthropodborne pathogens, could contribute to the spread of these agents among birds and mammals.

The results obtained do not demonstrate whether or not pheasants are reservoirs of the investigated bacteria, because the presence of antibodies does not necessary correspond to an infection. However, more accurate studies are needed because $P$. colchicus seem to be involved in the epidemiology of some tick-borne bacteria.

\section{REFERENCES}

1. Santilli F, Bagliacca M. Occurrence of eggs and oocysts of intestinal parasites of pheasant (Phasianus colchicus) in droppings collected in differently managed protected areas of Tuscany (Italy). Eur J Wildl Res. 2012; 58: 369-372.

2. Baneth G. Tick-borne infections of animals and humans: a common ground. Int J Parasitol. 2014; 44: 591-596.

3. Palomar AM, Santibáñez P, Mazuelas D, Roncero L, Santibáñez S, Portillo A, Oteo JA. Role of birds in dispersal of etiologic agents of tick-borne zoonoses, Spain, 2009. Emerg Infect Dis. 2012; 18: 1188-1191.

4. Hornok S, Kováts D, Csörgö T, Meli ML, Gönczi E, Hadnagy Z, et al. Birds as potential reservoirs of tick-borne pathogens: first evidence of bacteraemia with Rickettsia helvetica. Parasit Vectors. 2014; 7: 128.

5. Toma L, Mancini F, Di Luca M, Cecere JG, Bianchi R, Khoury C, et al. Detection of microbial agents in ticks collected from migratory birds in central Italy. Vector Borne Zoonotic Dis. 2014; 14: 199-205.

6. Norte A, De Carvalho I, Ramos J, Goncalves M, Gern L, Nuncio M. Diversity and seasonal patterns of ticks parasitizing wild birds in western Portugal. Exp Appl Acarol. 2012; 58: 327-339.

7. Dingler RJ, Wright SA, Donohue AM, Macedo PA, Foley JE. Surveillance for Ixodes pacificus and the tick-borne pathogens Anaplasma phagocytophilum and Borrelia burgdorferi in birds from California's Inner Coast Range. Ticks Tick-Borne Dis. 2014; 5: 436-445.

8. Mascarelli PE, McQuillan M, Harms CA, Harms RV, Breitschwerdt EB. Bartonella henselae and B. koehlerae DNA in birds. Emerg Infect Dis. 2014; 20: 490-492.

9. Ebani VV, Bertelloni F, Turchi B, Filogari D, Cerri D. Molecular survey of tick-borne pathogens in Ixodid ticks collected from hunted wild animals in Tuscany, Italy. Asian Pac J Trop Med. 2015; 8: 714-717.

10. Brouqui P, Bacellar F, Baranton G, Birtles RJ, Bjoërsdorff A, Blanco JR, et al. Guidelines for the diagnosis of tick-borne bacterial diseases in Europe. Clin Microbiol Infect. 2004; 10: 1108-1132.

11. Anderson A, Bijlmer H, Fournier PE, Graves S, Hartzell J, Kersh GJ, et al. Diagnosis and management of Q Fever - United States, 2013. Recommendations from CDC and the Q Fever working group. MMWR Recomm Rep. 2013; 62 (RR-03): 1-30.

12. Mineo TWP, Carrasco AOT, Raso TF, Werther K, Pinto AA, Machado RZ. Survey for natural Neospora caninum infection in wild and captive birds. Vet Parasitol. 2011; 182: 352-355. 
13. Raoult D, Marrie T, Mege J. Natural history and pathophysiology of Q Fever. Lancet Infect Dis. 2005; 5: 219-226.

14. Maurin M, Raoult D. Q Fever. Clin Microbiol Rev. 1999; 12: 518-553.

15. Sprong H, Tijsse-Klasen E, Langelaar M, De Bruin A, Fonville M, Gassner F, et al. Prevalence of Coxiella burnetii in Ticks After a Large Outbreak of Q Fever. Zoonoses Public Health. 2012; 59: 69-75.

16. Ebani VV, Nardoni S, Fognani G, Mugnaini L, Bertelloni F, Rocchigiani $\mathrm{G}$, et al. Molecular detection of vector-borne bacteria and protozoa in healthy hunting dogs from Central Italy. Asian Pac J Trop Biomed. 2015; 5: 108-112.

17. Ebani VV, Nardoni S, Bertelloni F, Rocchigiani G, Mancianti F. Tickborne infections in horses from Tuscany, Italy. J Equine Vet Sc. 2015; 35: 290-294.

18. Brouqui P, Parola P, Fournier P, Raoult D. Spotted fever rickettsioses in southern and eastern Europe. FEMS Immunol Med Mic. 2007; 49: 2-12.

19. Rudenko N, Golovchenko M, Grubhoffer L, Oliver JHJr. Updates on Borrelia burgdorferi sensu lato complex with respect to public health. Ticks Tick-Borne Dis. 2011; 2: 123-128.

20. Stuen S, Granquist EG, Silaghi C. Anaplasma phagocytophilum - a widespread multi-host pathogen with highly adaptive strategies. Front. Cell Infect Microbiol. 2013; 3: 31 doi: 10.3389/fcimb.

21. La Scola B, Raoult D. Laboratory diagnosis of rickettsioses: current approaches to the diagnosis of old and new rickettsial diseases. J Clin Microbiol. 1997; 35: 2715-2727.

22. Beninati T, Lo N, Noda H, Esposito F, Rizzoli A, Favia G, Genchi C. First detection of spotted fever group rickettsiae in Ixodes ricinus from Italy. Emerg Infect Dis. 2002; 8: 983-986.

23. Vitale G, Mansuelo S, Rolain JM, Raoult D. Rickettsia massiliae human isolation. Emerg Infect Dis. 2006; 12: 174-175.

24. Floris R, Yurtman AN, Margoni EF, Mignozzi K, Boemo B, Altobelli A, Cinco M. Detection and identification of Rickettsia species in the northeast of Italy. Vector Borne Zoonotic Dis. 2008; 8: 777-782.

25. Mura A, Masala G, Tola S, Satta G, Fois F, Piras P., et al. First direct detection of rickettsial pathogens and a new rickettsia, "Candidatus Rickettsia barbariae", in ticks from Sardinia, Italy. Clin Microbiol Infect. 2008; 14: 1028-1033.

26. Selmi M, Martello E, Bertolotti L, Bisanzio D, Tomassone L. Rickettsia slovaca and Rickettsia raoultii in Dermacentor marginatus ticks collected on wild boars in Tuscany, Italy. J Med Entomol. 2009; 46: 1490-1493.

27. Trotta M, Nicetto M, Fogliazza A, Montarsi F, Caldin M, Furlanello T, Solano-Gallego L. Detection of Leishmania infantum, Babesia canis, and rickettsiae in ticks removed from dogs living in Italy. Ticks Tick Borne Dis. 2012; 3: 294-297.

28. Wallménius K, Barboutis C, Fransson T, Jaenson TG, Lindgren PE, Nyström F, et al. Spotted fever Rickettsia species in Hyalomma and Ixodes ticks infesting migratory birds in the European Mediterranean area. Parasit Vectors. 2014; 7: 318.

29. Raoult D, Roux V. Rickettioses as paradigms of new or emerging infectious diseases. Clin Microbiol Rev. 1997; 10: 694-719.
30. Dubska L, Literak I, Kocianova E, Taragelova V, Sychra O. Differential role of passerine birds in distribution of Borrelia spirochetes, based on data from ticks collected from birds during the postbreeding migration period in Central Europe. Appl Environ Microbiol 2009; 75: 596-602.

31. Kurtenbach K, Carey D, Hoodless AN, Nuttall PA, Randolph SE. Competence of pheasants as reservoirs for Lyme disease spirochetes. J Med Entomol. 1998; 35: 77-81.

32. Kurtenbach K, Peacey M, Rijpkema SG, Hoodless AN, Nuttall PA, Randolph SE. Differential transmission of the genospecies of Borrelia burgdorferi sensu lato by game birds and small rodents in England. Appl Environ Microbiol. 1998; 64: 1169-1174.

33. Mannelli A, Nebbia P, Tramuta C, Grego E, Tomassone L, Ainardi R, et al. Borrelia burgdorferi sensu lato infection in larval Ixodes ricinus (Acari: Ixodidae) feeding on blackbirds in northwestern Italy. J Med Entomol. 2005; 42: 168-175.

34. Kipp S, Goedecke A, Dorn W, Wilske B, Fingerle V. Role of birds in Thuringia, Germany, in the natural cycle of Borrelia burgdorferi sensu lato, the Lyme disease spirochaete. Int J Med Microbiol. 2006; 296: $125-128$.

35. Taragel'ova V, Koci J, Hanincova K, Kurtenbach K, Derdakova M, Ogden NH, et al. Blackbirds and song thrushes constitute a key reservoir of Borrelia garinii, the causative agent of borreliosis in Central Europe. Appl Environ Microbiol. 2008; 74: 1289-1293.

36. Ebani VV, Cerri D, Fratini F, Ampola M, Andreani E. Seroprevalence of Anaplasma phagocytophilum in domestic and wild animals from central Italy. New Microbiol. 2008; 31: 371-375.

37. De La Fuente J, Naranjo V, Ruiz-Fons F, Hofle U, Fernandez De Mera IG, Villanúa D., et al. Potential vertebrate reservoir hosts and invertebrate vectors of Anaplasma marginale and A. phagocytophilum in central Spain. Vector Borne Zoonotic Dis. 2005; 5: 390-401.

38. Alekseev AN, Dubinina HV, Semenov AV, Bolshakov CV. Evidence of ehrlichiosis agents found in ticks (Acari: Ixodidae) collected from migratory birds. J Med Entomol. 2001; 38: 471-474.

39. Bjöersdorff A, Bergström S, Massung RF, Haeming PD, Olsen B. Ehrlichia -infected ticks on migrating birds. Emerg Infect Dis. 2001; 7: 877-879

40. Jahfari S, Coipan EC, Fonville M, van Leeuwen AD, Hengeveld P, Heylen D, et al. Circulation of four Anaplasma phagocytophilum ecotypes in Europe. Parasit Vectors. 2014; 7: 365.

41. Ebani VV, Cerri D, Fratini F, Ampola M, Andreani E. Anaplasma phagocytophilum infection in a fallow deer (Dama dama) population in a preserve of central Italy. New Microbiol. 2007; 30: 161-165.

42. Ebani VV, Verin R, Fratini F, Poli A, Cerri D. Molecular survey of Anaplasma phagocytophilum and Ehrlichia canis in red foxes (Vulpes vulpes) from Central Italy. J Wildl Dis. 2011; 47: 699-703.

43. Villanúa D, Acevedo P, Höfle U, Rodríguez O, Gortázar C. Changes in parasites transmission stage after pheasant release. J Helminthol. 2006; 80: 313-318. 